\title{
Bhutan Urban Policy Notes Urban Resilience
}

This paper is part of a series of four Urban Policy Notes that identify emergent challenges to Bhutan's increasing urbanization and its ramifications for growth, livability, and sustainability in line with the directives of the $12^{\text {th }}$ Five-Year Plan (FYP) for 2018-23 and the Vision 2020. The four notes are: (i) Regional Development, (ii) Municipal Governance and Finance, (iii) Affordable Housing, and (iv) Urban Resilience. These notes build on the long engagement between the Royal Government of Bhutan (RGoB) and the World Bank on urban issues as well as the operations under the Bhutan Urban Development Project I (1999-2006) and II (2010-19). This note specifically draws from the ongoing support to build a safe, sustainable, and climate-resilient Bhutan through the Hydromet Services and Disaster Resilience Regional Project, preparation of Bhutan's Strategic Program for Climate Resilience Project, Improving Seismic Resilience Project, and related technical assistance. It is intended to support the RGoB on key and emerging topics relevant in the context of increasing urbanization and vulnerability to weather, water, and climate hazards, and to guide the Bank's future analytical and investment support on urban- and resilience-related challenges.

\section{Executive Summary}

1. Bhutan's vulnerability to natural disasters and climate-related hazards requires better planning of settlements and enhancement of resilience in urban development and its expanded services. Located in the seismically active eastern portion of the Himalayan arc, Bhutan is exposed to hydro-meteorological hazards. Urban density is projected to increase from 37.8 percent (2017) to 56.8 percent (2047) of the total population. The impact of natural disasters and a changing climate have potentially devastating effects in terms of human lives lost, economic livelihoods destroyed, and losses in sectoral productivity. Furthermore, clustered settlements with high density population are also at higher risk to fire disasters. In 2016, floods affected the entire country, with major destruction in the South. Apart from dozens of households directly affected, the floods destroyed critical infrastructure and led to fuel and food shortages.

2. The RGoB recognizes the devastating impact that natural disasters and climate change are having and can have on Bhutan's economy and vulnerable communities. It addresses these challenges and opportunities in the country's main development plans. The $11^{\text {th }}$ FYP for $2013-18$ and the upcoming $12^{\text {th }}$ FYP for 2018-23 clearly reflect the urgency to enhance and integrate disaster and climate resilience in their developmental activities as two of the National Key Result Areas. There are, however, challenges to implement the activities.

3. Bhutan has a strong policy and legislative framework but with relatively weak implementation. Guided by the Local Governments Act and the Disaster Management Act of Bhutan, an enabling environment is in place to ensure the safety of people, assets, and services. However, the 2016 Performance Audit of Disaster Management indicates ineffective coordination among agencies; absence of hazard zoning maps and vulnerability assessments; lack of a central database to manage disasters; inadequate risk transfer mechanisms; inadequate fire safety measures in public buildings; inadequate application of safe construction practices; lack of proper planning, design, and workmanship in construction works; nonestablishment of Emergency Operation Centers, and inadequacies and inconsistencies in funding arrangements. These findings resonate in the Disaster Risk Management Strategy of Bhutan, which aligns with the Sendai Framework for Disaster Risk Reduction.

4. Bhutan's development of hazard maps and a geospatial database of infrastructure assets are at nascent stages. Geospatial analytics and related multi-hazard mapping are key components for integrating DRM into the urban planning process, enhancing service delivery and ultimately informing the risk reduction and emergency preparedness strategies. Thimphu Thromde has started to map utility services 
with geospatial data, realizing that a spatial platform (with all its assets) is the foundation for better planning, development, and resilience. Being a new discipline, the in-country capacity is thin. There are gaps in reliable and comprehensive hazard information (geological, hydrological, meteorological) and limited technical expertise to identify vulnerabilities and assess risks, which hinders the planning of settlements. At present, hazard maps are prepared on an as-needed basis, which leads to duplication and wastes resources.

5. The Thromdes are facing increased pressure for expanded service delivery, especially in urban areas. Fast urbanization has increased the demand for clean drinking water and managing stormwater runoff, wastewater, sewage, and solid waste. One measure of urban resilience is the quality of and access to utility services delivery in shocks (weather, water, climate, and earthquakes). This requires designating resources for operations and maintenance $(\mathrm{O} \& \mathrm{M})$; compromising on $\mathrm{O} \& \mathrm{M}$ can lead to faster depreciation of the investment and increase its vulnerability to disasters. Thus, integrating resilient infrastructure planning across sectors can help the Thromdes improve urban resilience.

6. The Royal Government of Bhutan can, based on the findings of this Urban Resilience Note, consider the following actions and activities to mitigate against disaster impacts and to help protect human lives, enhance economic livelihoods, and increase sectoral productivity:

- Establish a strong geospatially tagged information base for resilience planning, including a spatial analytics system, database management, hazard mapping, and risk assessment for decision-making.

- Strengthen the capacity and processes for systematically integrating urban resilience into infrastructure development, including into planning, design standards, financing options, and operations and maintenance practices.

- Strengthen urban service delivery with improved data and infrastructure resilience, through integration of resilient infrastructure planning across sectors.

- Leverage sources of disaster risk finance for timely emergency response and harness the private sector for enhancement of quality of infrastructure and services delivery.

- Reinforce critical infrastructure for preparedness and emergency response, hydromet and early warning services, and green infrastructure for urban resilience.

- Enhance citizen engagement by improving public awareness of and participation in disaster riskrelated planning and mitigation.

- Promote regional collaboration and learning to draw on lessons and capacity in the region on technically challenging issues that have regional dimensions, such as weather and climate services. 


\section{Introduction}

Bhutan is a small, landlocked country in the seismically active eastern portion of the Himalayan Arc, exposed to hydro-meteorological hazards. Flooding and landslides are common in monsoon season and cause recurrent damage to lives and assets. Extreme events cause significant losses to the economy. ${ }^{1}$ For example, 2016 floods affected the entire country and, in the South, caused major destruction (about 0.36 percent of 2016 gross domestic product). The floods destroyed critical infrastructure including roads, bridges, and buildings; affected about 100 households; and led to fuel and food shortages.

Bhutan is trending toward co-agglomeration of industrial and socio-economic activities and an intensification of centralized migration in urban areas, reflecting uneven and clustered geographical integration. This trend is similar to other early urbanizing countries. Thimphu Thromde, the capital city of Bhutan, in 2017, accounted for about 15 percent of the total population of 735,000. The 2017 Population and Housing Census notes that rural-to-urban migration accounts for 21.7 percent of the total population born in Bhutan and for 44.2 percent of the total migrant population.

Bhutan's population is projected to urbanize at a rate of 56.8 percent by 2047 , from 37.8 percent in 2017. ${ }^{2}$ Although urban areas are distributed over only around 1 percent of the total land area, the spatial integration of economies, connectivity, and access to utilities and markets and the proximity to socioeconomic services drive the high rate of urbanization. These trends have increased population density in urban areas, necessitating a growth-focused urban resilience strategy. One that contributes to equitable and resilient development and to Bhutan's goal of Gross National Happiness.

The country's vulnerability to natural disasters and climate-related hazards warrants greater planning for fast-growing urban settlements and expanded urban services. Furthermore, clustered settlements with high density population are also at higher risk to fire disasters. The greater concentration of people and assets means that the impact of natural and man-made disasters and a changing climate can be devastating in terms of human lives lost, economic livelihoods destroyed, and losses in sectoral productivity. The poorer segments of the population are the most vulnerable.

Urban low-income groups may lack access to quality infrastructure coverage and affordable safe housing and also may lack access to services and social networks to help cope with or respond to shocks. Experiences from the South Asia Region show that new migrants tend to settle in areas closest to the jobs and services they need. The migrants settle even if the areas are hazardous or restricted from development (hillside slopes, flood-affected areas, subsiding land) because of the low costs.

Resilient urban growth rests on a geospatially tagged decision support system that comprises wellcoordinated and fast-disseminating data, information, and analysis. Key elements include detailed hazard assessments and risk mapping of the built-up infrastructure; access to and use of such information in urban planning, building regulations, and urban expansion; improved preparedness of urban institutions and communities; and, early warning systems based on solid risk information, forecasting capacity, and dissemination systems.

Unplanned urbanization accrues vulnerabilities and requires risk-informed decision-making for redress. Redressing Bhutan's existing haphazard urbanization requires the development of two key datasets. First, a deeper understanding of the type and severity of risk profiles in different geographical

\footnotetext{
${ }^{1}$ In 2009, the total damages of Cyclone Aila and an earthquake were approx. 5.7 percent of 2009 gross domestic product (GDP); a 2011 earthquake resulted in damages of about 1.4 percent of 2011 GDP.

${ }^{2}$ National Statistics Bureau. 2018. Population Projections Bhutan 2017-2047. Thimphu: Royal Government of Bhutan.
} 
zones, especially for major urban settlements, that result from the ongoing economic and sociodemographic shifts. Second, a strengthened hazard, exposure, vulnerability, and risk information base.

Developing robust, reliable, and accessible geospatial information is critical. This geospatial information needs to be accessible and in formats that are usable by urban planners, service providers, and investment planners for decision-making. The actors can use the information to improve planning, prioritize investments, and address critical infrastructure gaps. In turn, this work can reduce Bhutan's exposure to property damage, household economic shocks, environmental degradation, and the incidence and spread of serious public health threats.

Urban resilience generally refers to the ability of a city or urban system to withstand shocks and stresses. ${ }^{3}$ Its preparedness and recovery capacity in the face of disasters depends on the appropriateness of policy decisions about investments in resilient urban infrastructure, technical upgrades, and the reach of early warning systems. Appropriate decision-making depends on solid risk information, forecasting capacity, and dissemination systems as well as on resilient buildings/land-use plans and mechanisms to enhance resilience (contingency plans) and transfer risk.

Effectively managing the interplay of fast urbanization and disaster/climate-change risks is the crossroad Bhutan must now navigate. A robust system to make informed decisions can protect development gains, adapt development to changing country trends/contexts, and prevent unsustainable development pathways, especially for urban areas. Specifically, informed decision-making can mitigate Bhutan's susceptibility to increasingly intense and frequent urban shocks and stresses (as compared to service and infrastructure failure for lack of robust risk information). In the aftermath of a hazard event, informed decision-making also can support fluid recovery and reconstruction, better delivering services to the citizenry and especially to the poor and the vulnerable.

This note provides an overview of the ongoing efforts of the Royal Government of Bhutan (RGOB), the challenges faced, and the proposed measures for strengthening urban resilience. Critical areas for further attention include:

- Establish a strong information base for resilience planning, including a spatial analytics system, ${ }^{4}$ database management, hazard mapping, and risk assessment for decision-making.

- Strengthen the capacity and processes for systematically integrating urban resilience into infrastructure development, including into planning, design standards, financing options, and operations and maintenance practices.

- Strengthen urban service delivery with improved data and infrastructure resilience, through integration of resilient infrastructure planning across sectors

- Leverage sources of disaster risk finance for timely emergency response and harness the private sector for enhancement of quality of infrastructure and services delivery.

- Reinforce critical infrastructure for preparedness and emergency response, hydromet and early warning services, and green infrastructure for urban resilience.

- Enhance citizen engagement by improving public awareness and participation in disaster riskrelated planning and mitigation.

- Promote regional collaboration and learning to draw on regional lessons and capacity for technically challenging issues that have regional dimensions such as weather and climate services.

\footnotetext{
${ }^{3}$ Leichenko, R. 2011. "Climate Change and Urban Resilience.” Current Opinion in Environmental Sustainability, 3:164-168.

${ }^{4}$ Spatial analytics provides an analysis of the city based on geospatial evidence. The purpose is to better understand the built environment and to identify gaps in access to infrastructure and services. These gaps can then be addressed through critical investments in service delivery such as solid waste, sewage, and water supply; management of critical assets; and inclusion of multi-hazard and flood-risk analysis, mapping of informal settlements, and other relevant aspects that impact urban planning, city growth, and development.
} 


\section{Status and Challenges}

The RGoB recognizes the devastating impact that natural disasters and climate change are having and can have on Bhutan's economy and vulnerable communities. It addresses these challenges and opportunities in the country's main development plans. The $11^{\text {th }}$ FYP for $2013-18^{5}$ and the upcoming $12^{\text {th }}$ FYP for 2018-236 clearly reflect the urgency to enhance and integrate disaster and climate resilience in their developmental activities as two of the National Key Result Areas. There are, however, challenges to implement the activities.

\section{Policy and Legislative Framework}

Bhutan has a strong policy and legislative framework but with relatively weak implementation. The country has a vision for developing a low-carbon path with enhanced resilience and has enacted strategies and guidelines as a roadmap. The novelty of the sector, however, means capacity needs to be built from the ground up. The Local Governments Act of Bhutan guides the governance of municipal governments, including on resilient service delivery and infrastructure. The 2013 Disaster Management Act of Bhutan (DM Act) ensures the safety and security of people, assets, and services by reducing and managing risks arising out of disasters, but it has implementation gaps.

The 2016 Performance Audit of Disaster Management provides insight on the effectiveness of the legislative, institutional, and governance mechanisms for disaster management, focusing on the DM Act. The report provides an overview of the non-compliance with the critical provisions of the DM Act, which impacts the resilience of urban settlements. These include ineffective coordination among agencies; absence of hazard zoning maps and vulnerability assessments; lack of a central database to manage disasters; inadequate risk transfer mechanisms; inadequate fire safety measures in public buildings; inadequate application of safe construction practices; lack of proper planning, design, and workmanship in construction works; non-establishment of Emergency Operation Centers; and inadequacies and inconsistencies in funding arrangements.

The Disaster Risk Management Strategy of Bhutan (2016) guides the implementation of disaster risk management (DRM) activities in line with national and international policies and priorities. It identifies key issues and gaps and recommends interventions (Box 1).

\section{Box 1. Disaster Risk Management Strategy of Bhutan}

Bhutan integrates global good practice into its policies and priorities. In formulating a vision statement for disaster risk management, the Department of Disaster Management (DDM) aligned Bhutan's framework with the Sendai Framework for Disaster Risk Reduction 2015-30.

DDM's Disaster Risk Management Strategy articulates government policies, principles, and expected results. The strategy also identifies priorities and focus areas to maximize the efficient allocation of limited financial and technical resources.

\begin{tabular}{|l|l|l|}
\hline Priority Actions & \multicolumn{1}{|c|}{ Key Issues and Gaps } & \multicolumn{1}{c|}{ Recommended Interventions } \\
\hline $\begin{array}{l}\text { Improving the } \\
\text { understanding of } \\
\text { disaster risks }\end{array}$ & $\begin{array}{l}\text { Lack of a multi-hazard atlas with } \\
\text { improved coordination among } \\
\text { responsible agencies. }\end{array}$ & $\begin{array}{l}\text { Synthesize existing data on hazards and } \\
\text { vulnerabilities in a usable format to inform } \\
\text { decision-making, incorporating disaster } \\
\text { risk management aspect. }\end{array}$ \\
\hline
\end{tabular}

\footnotetext{
5 (i) Carbon neutral/green and climate resilient development, (ii) Improved disaster resilience and management.

6 (i) Carbon neutral, climate, and disaster resilient development enhanced, (ii) Livability, safety, and sustainability of human settlements improved.
} 


\begin{tabular}{|c|c|c|}
\hline & & $\begin{array}{l}\text { Enhance capacity of responsible agencies to } \\
\text { improve data sets. }\end{array}$ \\
\hline $\begin{array}{l}\text { Strengthening } \\
\text { the risk } \\
\text { governance } \\
\text { system }\end{array}$ & $\begin{array}{l}\text { Absence of a policy framework } \\
\text { that enables integration of DRM in } \\
\text { developmental activities, although } \\
\text { mandated in DM Act } 2013 \text { and } \\
\text { highlighted as national key result } \\
\text { areas in the } 12^{\text {th }} \text { FYP. }\end{array}$ & $\begin{array}{l}\text { Formulate clear mainstreaming guidelines } \\
\text { with a suggested list of actions and make it } \\
\text { available to all local governments and key } \\
\text { sectors to enable integration of DRR into } \\
\text { their annual and five-year development } \\
\text { plans and programs. }\end{array}$ \\
\hline $\begin{array}{l}\text { Investing in } \\
\text { disaster risk } \\
\text { reduction for } \\
\text { resilience }\end{array}$ & $\begin{array}{l}\text { Reactive and fragmented funding } \\
\text { mechanisms for DRR activities. } \\
\text { Lack of tools to monitor } \\
\text { integration of structural and non- } \\
\text { structural disaster resilient features } \\
\text { in construction of critical } \\
\text { infrastructure. } \\
\text { Lack of sustainable risk transfer } \\
\text { mechanisms. }\end{array}$ & $\begin{array}{l}\text { Establish financial modalities as mandated } \\
\text { in DM Act 2013, including contingent } \\
\text { financing in the aftermath of a major } \\
\text { disaster. } \\
\text { Allocate adequate budget to assure disaster } \\
\text { resilient mechanisms. }\end{array}$ \\
\hline $\begin{array}{l}\text { Strengthening } \\
\text { disaster } \\
\text { management } \\
\text { capabilities }\end{array}$ & $\begin{array}{l}\text { Limited understanding of the } \\
\text { linkage between and the } \\
\text { importance of integrating climate } \\
\text { change adaptation and DRR in } \\
\text { developmental activities. }\end{array}$ & $\begin{array}{l}\text { Conduct studies to understand the risks and } \\
\text { to develop mainstreaming tools to be } \\
\text { adopted in the annual and five-year plans. }\end{array}$ \\
\hline
\end{tabular}

As per provisions of the DM Act, the Thromdes are mandated to prepare Disaster Management and Contingency Plans (DMCPs) by the start of the $12^{\text {th }}$ FYP. Thimphu and Phuentsholing Thromde have completed the exercise and the other two Thromdes are in the drafting process. While the Act clearly states the need to institute plans for continuity of critical services in the event of a disaster and to develop vulnerability maps with structural and non-structural measures, the initiatives are at an infancy and need further support. Both the Thromde and district DMCPs are based on inadequate information (visual observation, limited risk assessments, general community knowledge) and would require strengthening with reliable and geospatially defined risk information.

The principles to mainstream resilience are somewhat embedded in urban development plans, but lack of a legal framework hinders implementation. At present, the Ministry of Works and Human Settlement (MoWHS) prepares the urban development plans based on the Bhutan Building Regulations (BRR) 2018 (revised Bhutan Building Rules 2002), the National Human Settlement Strategy 2017, and the Spatial Planning Standards 2017. In response to the need for a legal framework to be able to enforce prepared plans and designs, the Department of Human Settlement (DHS) is drafting the Spatial Planning Act to improve spatially driven resilient urban planning. The National Human Settlement Policy, which is in the final stages of approval by the Cabinet, will support the preparation of this Act.

There are seismic building codes and a stringent approval processes for the designs and drawings of public and private buildings in urban areas, but compliance is a challenge. While some aspects of monitoring are in place in the Thromdes, a lack of technical and human capacity compromises monitoring and enforcement of building guidelines. The Building Code of Bhutan 2018 was formulated as a part of the BRR 2018. It sets out the importance of complying with the seismic building codes to ensure the safety of 
buildings against earthquake risks and the Green Building Design Guidelines 2013 to encourage adoption of green designs and sustainable technologies. The construction industry, however, has gaps in professionalism, quality assurance, and enforcing rules and regulations.

The increase in risks to fire hazards is recognized as one of the emerging challenges in urban areas. ${ }^{7}$ While the BRR provides fire-preventive measures for individual buildings, they are not systematically (and largely not) incorporated during implementation. The Department of Engineering Services is developing a guideline for fire safety in buildings, but the draft guideline requires deeper consultations. In parallel, the Fire Service Division under the Royal Bhutan Police, which is responsible for firefighting, is in the process of formulating a Fire Act. The draft of this Act has been submitted to the Ministry of Home and Cultural Affairs for its endorsement and further submission to the Cabinet.

The draft National Construction Industry Policy looks at enhancing professionalism, quality assurance, enforcement of rules and regulations in place, green growth, and monitoring and evaluation, which are critical aspects for integrating resilience in building construction. The MoWHS prepared the draft and the Gross National Happiness Commission is in the process of reviewing it.

The Ministry of Works and Human Settlement also is working on instituting a Council of Bhutanese Engineers. The purpose of the Council is to improve the service delivery of designs, drawings, and construction of infrastructure through registration and certification of engineers and architects working in Bhutan. It includes a regulated code of conduct to ensure accountability.

Agencies (including Thromdes) are mandated to maintain funds in their annual and five-year plans for mainstreaming disaster risk reduction (DRR) activities. Most investments to improve disaster and climate resilience and enhance the information base for hydro-met services are dependent on grants. This leads to fragmented funding mechanisms and poses a challenge to investing strategically in DRR activities.

Recovery and reconstruction activities require financial arrangements and risk transfer mechanisms to respond to disasters without affecting ongoing development plans. The Operational Guidelines for Disaster Financing 2017, prepared based on the DM Act, facilitates agencies to access funds for three DM activities: (i) immediate disaster response and relief activities; (ii) immediate restoration of essential public infrastructure and service centers; and (iii) recovery and reconstruction activities. The Ministry of Finance keeps a contingency reserve fund for the first two activities. For the third, the options are to: (a) re-prioritize within the agency's planned activities; (b) explore for additional resources from development partners or diversion of funds from other agency's planned activities; or (c) wait till resources are mobilized.

\section{Information Base}

Geospatial analytics and related multi-hazard mapping are key components for integrating DRM into the urban planning process. Bhutan's development of hazard maps and a geospatial database of infrastructure assets are at nascent stages. Next steps should include an evaluation of urban planning issues at the macro/meso level, including natural conditions (slopes, rivers, water bodies) and physical barriers (highway affecting slopes, water flow, runoff, fire suppressants), road networks, buildings, and opens spaces, among others. Then, more detailed analyses of hazards, exposure, vulnerability, and risks can be conducted. This will mitigate the exacerbation of existing urban risks.

Hazard mappings provide crucial information for siting infrastructure and for identifying the underlying vulnerabilities to map out potential risks. Lack of accurate and comprehensive hazard information (geological, hydrological, meteorological) and limited technical expertise to identify vulnerabilities and assess risks hinder the planning of settlements. At present, hazard maps are prepared on

\footnotetext{
${ }^{7}$ http://www.kuenselonline.com/risks-of-fire-hazards-increasing-in-thimphu/
} 
a need basis, which leads to duplication and wastes resources. A seismic risk assessment for Thimphu Thromde in 2013 outlined the need to improve data to enhance the quality of hazard maps and vulnerability assessments. ${ }^{8}$ Agencies, however, remain siloed and individually map hazards/implement hazard plans.

The first step for integrating resilience into urban planning is understanding the exposure of populations and inf rastructure to hazards (earthquakes, flooding, landslides). Currently, Bhutan does not have urban hazard maps. Like the hazard maps, agencies do not have a broad perspective of the risks posed by different hazards and the underlying vulnerabilities; they carry out their own mappings without the validation of technical third parties. To redress this situation, the RGoB has prioritized a systemic understanding of urban disaster risks to better plan the development of urban activities and investments.

Geospatial analysis plays a crucial role in identifying risks, enhancing service delivery, and ultimately informing the risk reduction and emergency preparedness strategies. While the development of infrastructure and utility services to meet public needs is a priority for the government, there has been no assessment of how resilient these assets are. There is no geospatial database of the service lines; this prohibits informed decision-making during emergencies. Only recently has Thimphu Thromde started to map utility services with geospatial data, realizing that a spatial platform (with all its assets) is the foundation for better planning, development, and resilience.

A consolidated data/information management system facilitates a systemic approach for managing infrastructure and sectoral activities while streamlining stakeholder coordination. Such a platform also supports an institutionalized system to asses risk, which is a priority for informed decision-making. The absence of a consolidated data/information management system impedes the development of resilient infrastructure.

Past practices to assess vulnerability were scattered and largely undocumented, which limits Bhutan's ability to prioritize investments for resilience. Bhutan adopted seismic codes for reinforced concrete buildings from India as a part of its building codes in the late 1990s (1997/98). Buildings constructed prior to the adoption of seismic building codes are highly vulnerable to seismic risks. Nonengineered buildings are not covered in the seismic building codes. This calls for identifying and assessing the safety of non-engineered buildings and for providing guidance to strengthen them, including rebuilding or retrofitting.

Retrofitting is a fairly new concept in Bhutan. Preliminary retrofitting trainings have been conducted. The trainings are based on the Guidelines for Structural Vulnerability Assessments and Retrofitting of Load Bearing Structures. However, the country's current field experience and engineering technical know-how are limited.

Bhutan still needs a street address system, even in urban areas. In 2015, Thimphu began developing a city address system to provide efficient door-to-door service delivery, ${ }^{9}$ but little progress has been made to date. Generally, visual landmarks are used to identify a location. This could pose huge challenges when responding to major disasters. Having a proper and easy-to-understand address system will not only increase the efficiency of service delivery but will enhance the effectiveness of emergency response.

\section{Quality and Access of Urban Services}

One measure of urban resilience is the quality of and access to utility services delivery in shocks (weather, water, climate, earthquakes). An increasing urban population and construction boom have

\footnotetext{
${ }^{8} \mathrm{http} / / /$ siteresources.worldbank.org/INTSOUTHASIA/Resources/223497-1378327471830/SeismicRisk_Bhutan_V5_forewordemail.pdf

${ }^{9} \mathrm{https}$ ://thebhutanese.bt/thimphu-thromde-comes-up-with-address-system-for-door-to-door-service-delivery/
} 
increased water usage and placed greater demands on the management of sewage, wastewater, and solid waste. Lack of mapped information of the layout of water pipes and drainage systems is a challenge even during normal times to identify points of problem when there is disruption in their functionality. Identification of problematic locations and maintenance is highly dependent on an individual's memory rather than institutional memory. Integrating resilient infrastructure planning across sectors, especially urban service delivery systems, should be of the highest priority. It helps protect development gains.

\section{The Thromdes face major challenges in managing drinking water, solid waste, wastewater and} sewage, and storm water.

- Drinking Water Management: Bhutan has a high per capita availability of water. But the water supply in urban areas is inadequate, with 57 percent of the population having access to water less than 12 hours a day. ${ }^{10}$ Urban water supply issues include an inadequate and unreliable supply, aging infrastructure, flooding and landslides, inadequate water treatment, seasonal drying up of sources, and constrained resources for operations and maintenance. ${ }^{11}$ Furthermore, one of the major challenges facing water utilities in Bhutan is the high level of water loss in the distribution networks and storage tanks.

To date, designing new systems has been prioritized over managing and improving existing networks. It is imperative to better understand the cascading effect of poor operations and maintenance of the water system, such as non-revenue water (NRW) losses from inaccurate metering, illegal connections, and leakages.

Without resilience planning, including proper management of NRW, infrastructure could become unusable or damaged during its economic life. For instance, water extraction facilities that are installed near water sources can dry up and water pipes and related infrastructure can burst because of cold weather, causing water shortages. Incorporating weather risk information into infrastructure planning is a necessity.

- $\quad$ Solid Waste Management: The Bhutan State of the Environment Report 2016 by National Environment Commission (NEC) notes that the country is seeing an increase in the solid waste generated, with the two urban centers of Thimphu and Phuentsholing facing challenges in municipal waste disposal.

Thimphu Thromde produced about 50,000 kilograms of waste every day in 2009; by 2020, an estimated 81,000 kilograms of waste will be produced every day in the city. ${ }^{12}$ The existing waste management system in Thimphu Thromde is under-equipped and struggling to service the increased waste production. Solid waste from Thimphu is now dumped at Memelhakha landfill, which is an open waste disposal facility. Its location at an uphill of a tributary to the Thimphu River poses health risks to the local population with ground and surface water contamination from untreated leachate.

The composition of urban waste is shifting from biodegradable to non-biodegradable, which increases the dangers of contamination. Regulations and resources for infrastructure and capacity building, combined with enhanced awareness and participation by urban communities, are necessary to address the issues of solid waste management.

- Wastewater and Sewage Management: NEC surveys indicate that Bhutan's water resources are healthy only at the macro level. The risk of pollution is a severe threat in cities such as Thimphu and

\footnotetext{
${ }^{10}$ Urban Water Supply - Status and Plan, Department of Engineering Services, MoWHS, 2014 (p. 8).

${ }^{11}$ Urban Water Supply - Status and Plan, Department of Engineering Services, MoWHS, 2014 (p. 37 ).

12 https://www.chinadialogue.net/article/show/single/en/4322-Bhutan-s-modern-face
} 
Phuentsholing, where the discharge of waste oil and other effluents is a major source of water pollution. Studies have found significant levels of Escherichia coli in Bhutanese rivers. ${ }^{13}$

The current wastewater facility in Thimphu Thromde treats only about 17 percent of the wastewater generated and the rest of sewerage flows directly into the river. This flow of waste makes the river water unfit for human consumption. According to Thimphu Thromde, less than 15 percent of total households in the city are connected to the sewer system and the rest rely on individual septic tanks. Overflow of raw sewage from manholes has been exacerbated by lack of funds to resolve wastewater management problems.

Future urban resilience plans should consider new wastewater treatment plants as a priority to meet the shortfall in treatment capacity and to develop trained water and sanitation specialists to provide these critical urban services.

- $\quad$ Storm Water Management: Under the Strategic Program for Climate Resilience, a report has been drafted on Climate Smart Human Settlement Planning and Development in Samdrupjongkhar Thromde. The draft report indicates that management of storm water is a key issue, as inadequate stormwater drains along roadsides can cause flooding.

Some of the urban plans include provision for fire hydrants but many do not. The lack of technical expertise on fire-fighting equipment among planners and local plan developers poses a challenge for incorporating fire safety measures into the urban plans. At this stage, there is very limited dialogue among relevant agencies on this issue such as the Department of Human Settlements and the Fire Service Division. Better coordination among these agencies can help strengthen fire safety measures at the planning level and eventually at the implementation level. This is critical given the Fire Service Department currently cannot meet the country's need for fire-fighting trucks.

Improved coordination among service providers is key to better planning and providing service lines in urban centers. If the fiber optics, telecommunications, and electricity lines are laid in a duct system, the management and maintenance of assets is much more efficient. At present, the country installs utility lines only when it works on roads. Bhutan needs better coordination and planning among utility service providers.

Operation and Maintenance $(O \& M)$ is essential for a developing country like Bhutan to sustain the effectiveness of its capital investments and service delivery. However, this is a challenge in Bhutan with limited technical and financial resources for maintenance. Compromising on the $\mathrm{O} \& \mathrm{M}$ could lead to faster depreciation of the investment made and to increasing its vulnerability to disasters. Lack of O\&M-related budgets are also a limiting factor in the choice of appropriate capital investments in hydromet observation and monitoring equipment.

Recognizing the major role played by the private sector in developmental activities, there is a need to strengthen the role and capacity of private sector in the resilience agenda. While all plans and policies are prepared by government agencies, the private sector develops the infrastructure, including important public buildings. The private sector has the option to use different kinds of construction materials and methodologies, and their choices can have significant bearing on the resilience of the infrastructure. National contractors do not have sufficient technical and personnel capacity to construct urban services that meet international standards. It is very important for the private sector to understand the resilience aspects of infrastructure and to build their capacity accordingly.

13 2017, The Global Waterkeeper Alliance and Clean Bhutan. 


\section{Critical Infrastructure}

It is important to have critical infrastructure, such as Emergency Operation Centers, Search and Rescue facilities and adequate infrastructure for the National Center for Hydrology and Meteorology (NCHM), to host and sustain critical services for emergency preparedness training and capacity and for weather and climate information. The Department of Disaster Management has conducted several search and rescue trainings and invested in the procurement of search and rescue equipment. It is a challenge to sustain the built capacity, as there is no facility to consolidate the efforts. Similarly, it is a challenge to sustain the investments made in terms of data collection and storage without an enabling system to connect with data provider agencies, such as the NCHM. NCHM has become an autonomous body with the mandate to provide hydromet and climate services and early warning information that underpins alerts and advisories to main weather dependent sectors such as agriculture, tourism, aviation urban, hydropower and disaster risk management. NCHM is facing constraints in terms of its location and requires greater support for adequate infrastructure that meets its needs for a growing institution.

\section{Capacity Building, Advocacy, and Knowledge Sharing}

To meet the increased needs of urbanization, continuous capacity building is needed to improve the technical capacity of the Thromdes and the relevant technical agencies. This includes the Department of Engineering Services (DES), Department of Human Settlements (DHS), Department of Disaster Management (DDM), and National Center for Hydrology and Meteorology (NCHM). The technical agencies have invested in building capacity to carry out their day-to-day functions. However, the agencies rely on international consultancy services for specialized tasks such as risk assessments, structural vulnerability assessments, ground water studies, and integration of disaster risk reduction and climate resilience into urban development plans. Gaps in specialized technical capacity need to be assessed and investments need to be made to build essential technical capacities with sustainable management options.

While the integration of climate and disaster risk management in development planning is a crosscutting priority for the RGoB, its implementation and monitoring are at a nascent stage. The national disaster risk management framework prioritizes investments to build resilience. Its aim is to finance structural and non-structural resilience measures as drivers of poverty reduction, job creation, and economic growth. The challenge lies in stakeholders' readiness to integrate resilience. The long-term benefits of investing in resilience become obvious to stakeholders as they recognize the importance of integrating resilience in urban development when recurrent and even minor hazards can cause significant and repeated damages.

Collective citizen engagement can help maintain the built systems. Agencies such as the Department of Disaster Management and the Department of Geology and Mines recently started awareness programs through the Bhutan Broadcasting Services, the only national television channel, TV ads, and newspaper ads, among others. The messaging still needs to explain the probability of hazard events (flooding, landslides, epidemics from waste management, water management, and public infrastructure use) so that the general public is not alarmed but better prepared for the events. For example, one of the main problems in Thimphu City is manholes are used to dispose of waste (household, plastic, and other wastes, which clogs the pipes), and the metal items from the manholes (the lids) are sold to scrap dealers.

Strengthening the partnerships between technical agencies and the Royal University of Bhutan can deepen research and leverage developmental activities with emerging technologies. One of the main constraints to assess the vulnerability of buildings is the lack of Bhutan-specific material properties. Similarly, studies on in-country construction technologies is highly limited. Effective partnerships between the engineering colleges and technical agencies (Department of Engineering Services) can expedite detailed research on construction material properties, construction technologies, and labor and material coefficiencies for the Bhutan Schedule of Rates. This work supports the next phase of development: guidelines 
for resilient construction. Such partnerships are key to sustain and advance technical know-how, data, and knowledge transfer.

Establishing partnerships with neighboring countries to increase capacities and access hydromet data and services would bring significant economies of scale to Bhutan as a small, landlocked country. The climate and weather patterns facing Bhutan are transboundary and are best monitored, understood, and predicted by taking regional and global perspectives. Moreover, there is a demand for Bhutan-specific data from regional centers and a demand for regional products and information that the Bhutan National Center for Hydrology and Meteorology can use. ${ }^{14}$

\section{Recommendations for Enhancing Urban Resilience}

This section explores opportunities to strengthen urban resilience in Bhutan. It encompasses policy directions and actions that may be tailored to address resilience-related priorities in different urban contexts. A summary of recommendations is provided in Box 3. A list of analytical works that the World Bank can potentially support to materialize some of the proposed recommendations is listed in Annex 1.

\section{Strengthening the Enabling Environment for Urban Resilience}

$>$ Strengthen Policies. Acts and policies are in place and under preparation to support an enabling environment for urban resilience. Policies are needed to encourage institutional coordination, strengthen service delivery, and reassess the existing ones in terms of operationalization. Specific areas of attention include:

- Formulate a Resilience Information Policy to help strengthen the information base for resilience by providing clarity and agreements on the collection, storage, and sharing of data and information and by creating a platform to update and share information organically. This will help improve disaster risk assessments and identify priorities to integrate disaster risk management in development activities.

- Formulate a Hydromet Services Delivery Policy to help strengthen the linkages between the National Center for Hydrology and Meteorology (NCHM) and end users, by identifying priority sectors and their hydromet information needs. Currently, the NCHM has drafted a concept note for this policy and has sought support from the World Bank for the development of this policy.

- Finalize and endorse Guideline for Fire Safety in Buildings to help mitigate fire risks in clustered settlements with high population density. This will strengthen the incorporation of fire mitigation in individual buildings and local area plans as a whole.

$>$ Prepare Action Plans. The draft National Human Settlement Policy and the draft National Construction Industry Policy for their operationalization need to have equally robust action plans. Implementation of these policies involves a variety of stakeholders, various levels of the government, and the private sector. It is, thus, critical to prepare an action plan to implement these policies, to build the capacity of relevant stakeholders, and to create awareness on policy implementation.

> Strengthen Institutional Coordination between DDM, DHS, DES, NCHM, and the Thromdes. While final expected outputs and outcomes are tagged to an individual agency, implementation of policies demands strong institutional coordination. Information flows that are coordinated and checks and balances that are institutionalized better-regulate policy implementation, across the different levels of government and in third-party engagement. Specific coordination for the implementation of action

\footnotetext{
${ }^{14}$ http://documents.worldbank.org/curated/en/773761467999701648/pdf/98534-REVISED-WP-P148430-PUBLICBox393196B.pdf
} 
plans in the areas of urban resilience, geospatial data management, hydromet services, infrastructure planning, implementation, and monitoring are priorities for operationalization of the well-formulated polices and identified key national result areas.

> Carry Out and Update Analyses and Technical Assessments. An improved understanding of contextspecific vulnerabilities and key issues is needed. Priority assessments include:

- Conduct vulnerability assessment of buildings, especially in the urban core areas. This would provide guidance on strengthening unsafe buildings, targeting those constructed before the adoption of seismic building codes, and understanding the overall vulnerability of the settlements. Based on the findings, a policy note could be formulated on the use of mechanisms (such as government subsidies and tax waivers) to encourage home owners to retrofit or reconstruct their homes. Findings will also inform preparedness and emergency response mechanisms.

- Assess the challenges in enforcing approved drawings and building designs on an implementation level. During construction, there is a strong need to assess the compliance with and monitoring of the Bhutan Building Rules and Designs. This will help uncover the constraints and gaps in enforcement of the approved drawings. While building regulations, scrutiny of plan drawings, and certain aspects of monitoring are in place in the four Thromdes, this could be developed as a comprehensive package from the design to implementation phase including monitoring to include resilience and urban development regulations. ${ }^{15}$

- Put in place regulations to clarify accountability for maintaining the quality of construction and for complying with drawings and designs. Adequate training, testing, and preparedness should be provided so that operators and regulators can acquire the right expertise, knowledge, and capacity. This will help to ensure that codes, standards, and best practices are followed with integrity to achieve the desired resilience. An initiative of the MoWHS aimed to strengthen the quality of monitoring and the implementation of construction works includes the proposal to establish an Engineering Council and to coordinate with vocational training institutes as per the draft National Construction Industry Policy. A brief on the World Bank's Building Regulation for Resilience Program which supports development of more efficient and effective building regulatory frameworks.is provided in Annex 2.

$>$ Develop a Comprehensive Disaster Risk Management Financial Strategy. It is important to put in place disaster risk retention tools that cover public and private properties. These tools should have the capacity to contain high-frequency, low-impact events and to establish disaster risk transfer mechanisms for high-impact, low-frequency events.

\section{Building the Information Base for Urban Resilience}

\section{$>$ Databases and Coordination}

- Establish a comprehensive geospatial data platform to effectively coordinate agencies. This is fundamental to prepare multi-hazard maps and to carry out risk assessments, especially for a small country with limited resources and technical capacity. Networking stakeholder agencies strengthens coordination, clarifies responsibilities, and has a ripple effect. Networked agencies are better sequenced for developing hazard maps and vulnerability assessments with urban planners and for developing common policies to strengthen collection, storage, and data sharing. It is recommended to organize country-level workshops, integrating government departments in charge of DRM activities on risk awareness and analysis, highlighting the importance of inter-agency

\footnotetext{
${ }^{15}$ References can be taken from the initiative led by GSURR which is working to promote a new building policy and regulatory strategy for the World Bank Group. It specifically seeks to develop and promote a new stream of activities to increase regulatory capacity and promote a healthier and safer built environment.
} 
coordination, and jointly (DDM, DES, DGM, DHS, and others) developing risk assessment plans. Improving geospatial exposure data (population density, buildings, roads, service utilities) can help to mitigate the negative effects of disasters and to increase efficacy of urban resilience over the long term.

- Establish a geospatial database of a Thromde's infrastructure assets. This is key to better planning, development, and enhanced resilience. There is a need to properly document existing service delivery facilities (water supply pipelines and other utility networks) in one data management center. This would facilitate the provision of services during normal periods and, more critically, augment responses during emergencies. A common methodology and database to record assets should be agreed upon and implemented in all Thromdes. Such an initiative should be extended to the urban centers of districts and at a later stage, to all settlements. That way, the database gradually covers the entire country.

- Integrate multi-hazard risk assessments in disaster management and contingency plans. Disaster management and contingency plans for Thromdes and districts can be improved with integration of risk information. To enhance preparedness at the community level, the community-based DRM and Early Warning approaches in these plans should be tested at regular intervals. Therefore, simulation exercise based on these plans and updating of these plans are recommended to be a part of the annual plans of Thromdes and districts.

- Establish a geospatially tagged city address system. This is critical for enhancing service delivery and effective communication during disasters. The Thimphu Thromde should revive its 2015 initiative. Other Thromdes should begin establishing an address system. Later, this can be expanded to the entire country.

- Think through the resiliency of data management. There is a need to understand and agree on the use of resilient data storage systems and to establish back-up plans. These plans must include coordination with service providers (power and telecom agencies) to ensure minimal disruption to the access and use of data and information during emergencies.

\section{Information-Driven Planning}

Having the geo-located hazard maps, vulnerability assessments, and risk mapping in place are critical elements of urban resilience. They bring out the impacts on interconnected systems and the stress- or shockabsorbing capacity, behavior, and performance of the systems when subjected to disasters. Hence, alternate supply routes and critical operational planning can be adopted.

- Adopt information-driven planning systems that integrate resilience factors. This can better identify the magnitude of risks and required preparations. Preparing multi-hazard maps and carrying out vulnerability assessments are urgently needed to comprehensively assess risk in urban areas at the local and national levels. A comprehensive assessment helps identify the risk reduction and emergency preparedness strategies that can be integrated into the urban planning and development process. Data-driven analyses can provide the basis to formulate effective urban resilience policies and strategies, with guidance based on population, land cover, and spatiallydetailed accessibility information.

- Promote and adopt the use of data-driven analyses outputs for policy and financial planning. Such planning is advantageously geared for enabling preparedness and faster emergency response. The benefits of such planning include reducing existing and/or potential risks in built-up areas; limiting the creation of new risks by directing urban development and expansion into areas that are safer 
and/or less vulnerable; and, improving the urban design and the efficient allocation of infrastructure for civic needs.

\section{Improving the Quality and Access of Urban Services for Enhancing Urban Resilience}

$>$ Management of drinking water supply, solid waste, sewage, and stormwater

- Enhance effectiveness and efficiency of service delivery. A better understanding of the wider issues, such as non-revenue water, is essential to plan for future network expansions. Furthermore, it is critical to look at how green infrastructure, such as using natural and constructed wetlands for secondary/tertiary treatment of storm water and wastewater, can be incorporated in settlement planning and implementation. Global evidence strongly shows that the use of natural and constructed wetlands can lower cost of and is a very effective instrument in treatment of storm/waste water. Currently, such water largely is left to flow untreated into the Bhutanese rivers, which increases the health risks for populations downstream and affects the ecological quality of rivers. Measures to conserve urban wetlands and support the use of natural and constructed wetlands can be vitally important not only to treat water but also as flood protection zones.

\section{$>$ Incorporation of Fire Safety measures in local area plans}

- Enhance coordination and capacity for fire hazard management. Close coordination among the Department of Human Settlement, Thromdes, Districts, and the Fire Service Division is essential to better plan for fire hazards. Understanding the functionalities of available equipment for fire management will facilitate streamlined plans for locating the equipment sets as a part of the overall development plan. Options to connect fire hydrants to the drinking water supply can be explored during the planning stage. In addition, regular drills and $O \& M$ of the fire hydrants are important to raise awareness among the community and to ensure the equipment sets are always operational.

\section{$>$ Private Sector Services Delivery}

- Carry out an assessment to understand how an enabling environment can be created for the private sector to be more engaged in enhancing the resilience of infrastructure development. The government should provide opportunities for the private sector and other stakeholders to participate in the development of resilient cities. This would include mapping investment opportunities and market potentials and raising awareness on the importance of quality of infrastructure to enhance its resilience in the face of natural disasters.

\section{$>$ Siting and Location}

- Incorporate hydrometeorological risks in siting infrastructure and invest in building the capacity for related infrastructure. It is important to prepare masterplans to manage utilities and to identify the infrastructure required to meet the needs of a growing population (based on the projection of population growth). Past experience and needs indicate that innovative technologies to enhance the performance of infrastructures and the role of private sector in management of service delivery should be explored.

- Raise community awareness through utility management planning. An informed population can advocate for change, provide implementation oversight, and report any misgivings. This can help address the country's challenges of an inadequate supply of drinking water and the management of solid waste and sewage.

\section{Coordination for Sector Services}

- Improve coordination among service providers to optimize the use of resources and the efficient delivery of utility services. Regular coordination meetings among service providers, such as the Bhutan Power Corporation and Bhutan Telecom, should be led by the Thromdes. The meetings 
should, to the extent possible, discuss work programs for coordinating the implementation of works on the ground for service delivery.

\section{Operation and Maintenance}

- Plan and budget for Operation and Maintenance $(O \& M)$. This has to be integral to the capital investments. O\&M planning and budgeting can be done through different methods, such as using public-private partnerships with viability gap financing or other risk-sharing models.

\section{Critical Infrastructure and preparedness capacity}

$>$ Establish and Operationalize the National Emergency Operation Center (NEOC). This needs to be established and made functional to fully benefit from other investments. The NEOC would allow stronger data and information sharing with other agencies and improve coordination with local and national agencies, especially during a disaster.

Dstablish a Search and Rescue Center. This would facilitate the establishment of systematic capacity building and consolidate investments in the equipment for Search and Rescue.

$>$ Establish a dedicated office building for NCHM. This would allow NCHM to expand its facilities and to build its capacity in terms of infrastructure and ICT facilities.

$>$ Strengthen emergency communication network and equipment. In parallel to operationalizing emergency operation centers and search and rescue teams with enhanced alert and warning communications, there is a need to assess the reliability of existing communication networks during emergencies. Such an assessment should look at both equipment, system interoperability, communication networks, human resources and standard operating procedures to communicate between EOCs, early warning information providers, government authorities and public.

\section{Capacity Building, Advocacy, and Knowledge Sharing}

$>$ Conduct an assessment on the current capacity and gaps of the related agencies. There is a strong need to invest in capacity building to advance the urban resilience agenda. In order to invest strategically in capacity building, an assessment needs to be conducted on the current capacity and gaps of the related agencies. Strategic discussions should be taken up by the relevant technical agencies with the Royal Civil Service Commission, Department of Adult and Higher Education under the Ministry of Education, and the Ministry of Labor and Human Resources. The discussions can plan for providing scholarships to pursue the required specializations and understanding job opportunities. Capacity building should also provide avenues for specialized training in geospatial tools, hazard vulnerability/catastrophe models, and shared data analysis and interpretation for technical staff from government departments.

$>$ Promote the knowledge of an eco-city concept, including Climate Smart Planning. At the ground level, resilience is integrated into urban planning through eco city concept planning, keeping adequate buffers, and ensuring green multi-use spaces.

- For example, construction is not allowed on slopes above 54 percent, allowing only one to two floors on slopes between 30-54 percent. Awareness programs are carried out based on hazard mapping for vulnerable settlements. Planning would factor these in to include the appropriate guidelines on building heights and setbacks and the appropriate designation of green areas, cultural heritage, and recreational spaces.

- To minimize the impact of climate change in these highly vulnerable urban regions, urban planners also need to integrate climate-resilient re-design protocols and to formulate climate-smart land use plans (LUPs) for housing, public works, critical municipal infrastructure, and green spaces. They should adhere to the principles of compact and resource-efficient urban design. 
$>$ Incorporate citizen-centered mechanisms in developing resilience strategies. This can convene multiple community actors to build sustainable resilient policies and to act in the community. This highlights the need to engage the public in maintenance of service delivery infrastructure. It is also important to conduct regular drills involving the public to understand the preparedness level as well as to prepare for responding during a disaster.

$>$ Strengthen partnerships between technical agencies and the Royal University of Bhutan. Partnership opportunities should be explored in research-deficient areas such as construction material properties and construction techniques that would feed into priority guidelines. As such, partnerships are at a nascent stage in Bhutan. It would be pivotal to have action plans developed and to pilot engagements carried out with coordination at both the policy-making and implementation levels.

$>$ Strengthen partnerships with its neighboring countries. Bhutan should explore collaborations with regional and international organizations for regional and country-specific satellite data for hydromet and climate data and shifts in land formations. This data and information can significantly strengthen hazard mapping and risk analysis.

$>$ Explore opportunities to enhance regional collaboration through capacity building and knowledge sharing. Bhutan is a member of the South Asia Hydromet Forum (SAHF) led by the World Bank, which is a mechanism for providing knowledge sharing, capacity development, and regional collaboration on Early Warning Systems and hydromet services. This is an important agenda in the context of urban resilience given the substantial hydrometeorological risk that Bhutan faces. The World Bank is also exploring opportunities to carry out analytical work to better understand the context of individual countries in the region. At the same time, it is facilitating knowledge exchange, enhancing cooperation, and strengthening institutions in the countries to promote urban resilience. These are important platforms from which Bhutan can draw lessons learned and to which Bhutan can help build the knowledge base. 


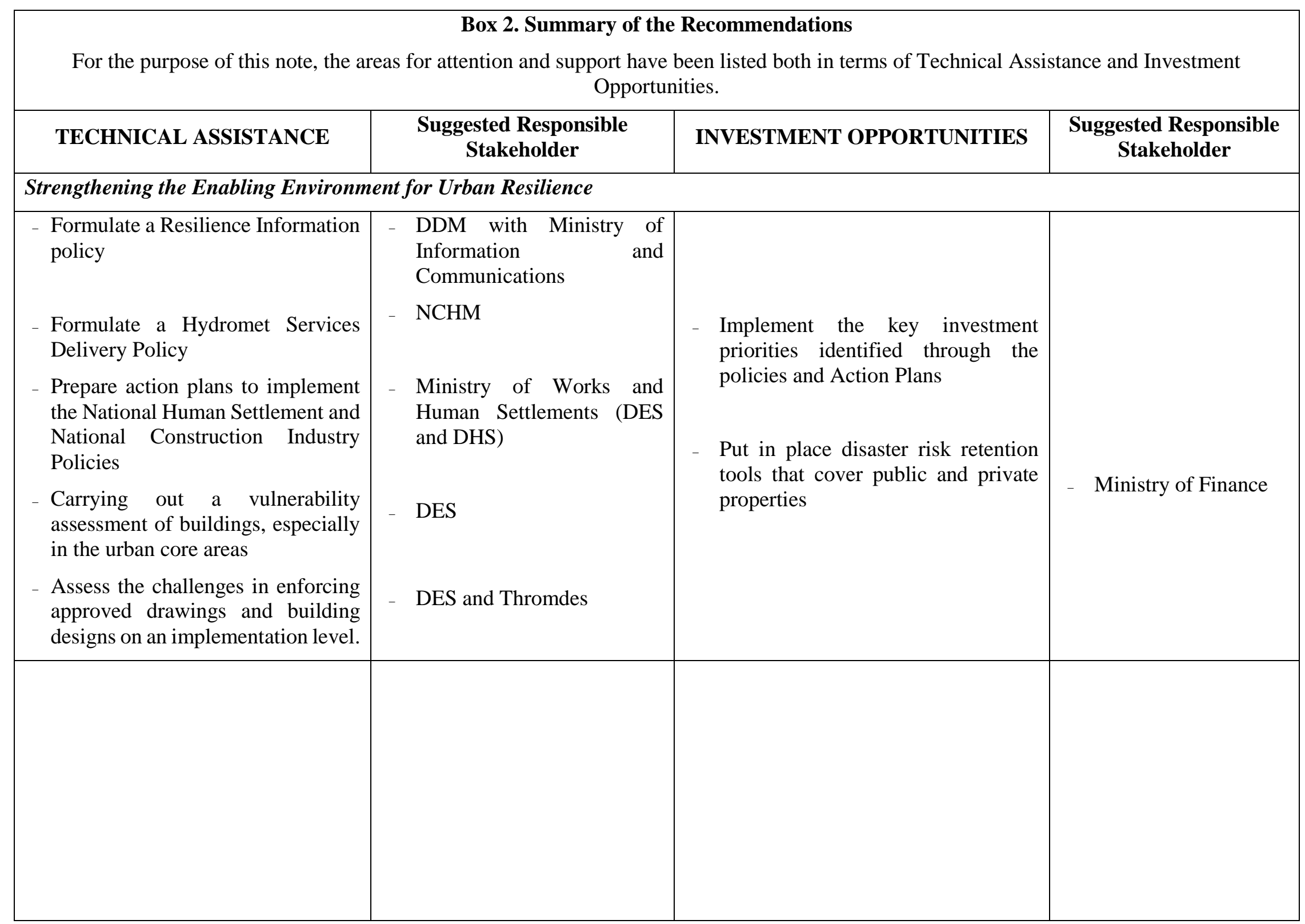




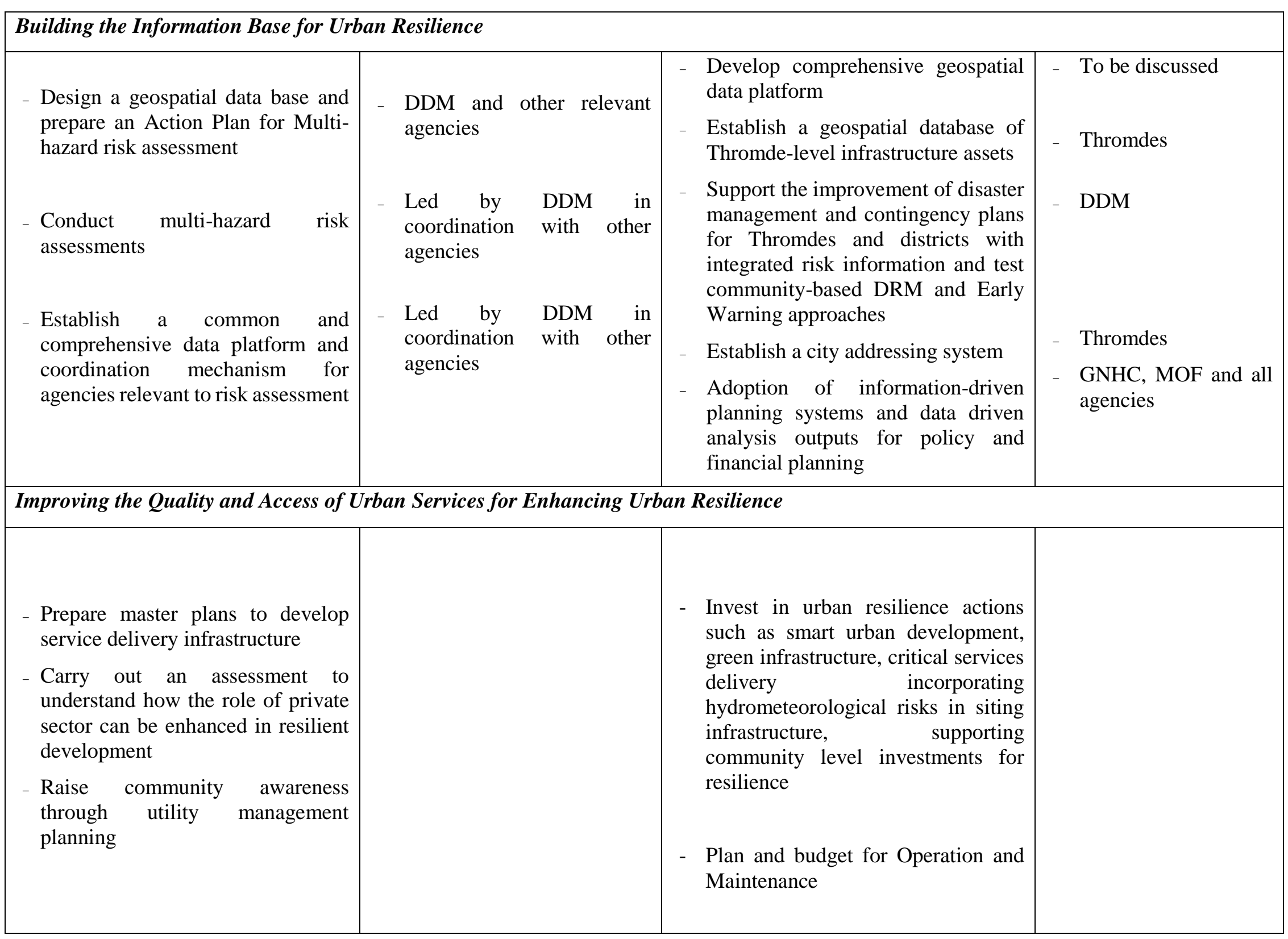




\begin{tabular}{|c|c|c|c|}
\hline \multicolumn{4}{|c|}{ Establishing Critical Infrastructure and Preparedness Capacity } \\
\hline $\begin{array}{l}\text { - Support for preparedness capacity } \\
\text { at national, district and community } \\
\text { levels with community engagement } \\
\text { (Institutional and CBDRM) }\end{array}$ & - DDM & 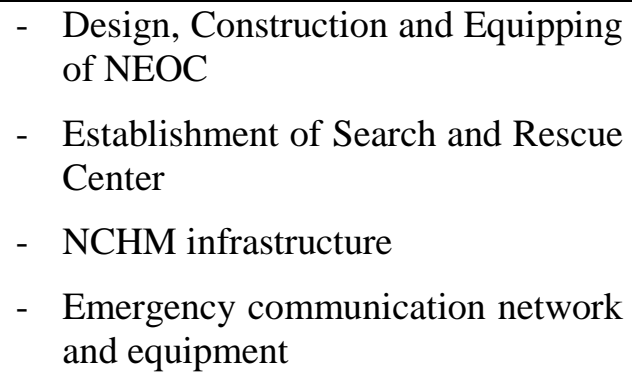 & $\begin{array}{l}\text { - DDM } \\
\text { - DDM } \\
\text { - NCHM } \\
\text { - } \begin{array}{l}\text { DDM with other } \\
\text { relevant agencies }\end{array}\end{array}$ \\
\hline \multicolumn{4}{|c|}{ Build Capacity, Advocacy, and Knowledge Sharing } \\
\hline $\begin{array}{l}\text { - Conduct an assessment on the } \\
\text { current capacity and gaps of the } \\
\text { related agencies to advance urban } \\
\text { resilience } \\
\text { - Build capacity to advance the urban } \\
\text { resilience agenda } \\
\text { - Strengthen partnerships between } \\
\text { technical agencies and the Royal } \\
\text { University of Bhutan } \\
\text { - Build partnerships with } \\
\text { neighboring countries and absorb } \\
\text { regional knowledge }\end{array}$ & $\begin{array}{l}\text { - DDM } \\
\\
\text { - MoWHS, Thromdes and } \\
\text { DDM } \\
\text { - Individual agencies and RUB } \\
\text { - To be discussed }\end{array}$ & 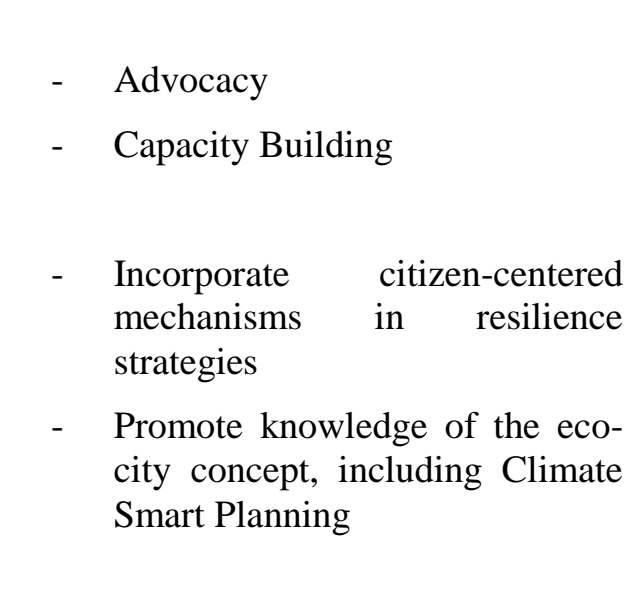 & $\begin{array}{l}\text { - CSOs } \\
\text { - Individual agencies in } \\
\text { coordination with } \\
\text { CSOs } \\
\text { - Government agencies, } \\
\text { CSOs, private sector } \\
\text { - Government agencies, } \\
\text { CSOs, private sector }\end{array}$ \\
\hline
\end{tabular}




\section{Annex 1: Analytical Work the World Bank Group Can Potentially Support}

1. Review and assess the Thimphu Structure Plan (TSP). The purpose of this review would be to drill down on particular topics to: (i) identify potential modalities and interventions for technical assistance and or systems upgrading; (ii) propose locations or screening criteria for civil works under the TSP and develop remaining local area plans (LAPs); and (iii) implement and maintain/manage arrangements for services or investments.

2. Promote and invest in urban resilience in South Asian cities. The overall objective of this activity is to promote urban resilience in selected South Asia Region cities through analytical work, knowledge development, and capacity building. The activity also will build capacity in prioritized areas and inform national governments, municipal authorities, and the World Bank on how to better target and finance potential urban resilience programs.

3. Develop Action Plan for multi-hazard risk assessment and design of geospatial database for resilience. This technical assistance (TA) will help improve disaster risk assessments and identify priorities to integrate disaster risk management in developmental activities. The purpose of this TA is to improve the understanding of disater risks through improved coordination mechanisms and information sharing.

4. Strengthen the resilience of the built up environment through the Building Regulation for Resilience Program. This program supports promotion of effective building regulatory frameworks through three main areas of intervention: (i) supporting best practice national legislative frameworks, national institutions and incentives that promote safe building practices; (ii) assisting in modern and locallyappropriate building code development and maintenance; and (iii) improving local systems of building and land use regulation implementation.

5. Strengthen disaster risk management and climate change adaptation policies in the South Asia Region. The objective of this TA is to help selected South Asia Region countries, including Bhutan, to formulate and implement key policy and institutional actions for building resilience. 


\section{Annex 2: Building Regulation for Resilience Program}

The World Bank's Building Regulation for Resilience (BRR) Program provides technical assistance to support low- and middle-income countries to reduce their physical risks in the built environment through regulatory enhancements that both improve resilience to disasters and achieve economic development goals. Buildings are an essential component of societies and economies; if built and maintained effectively, they can provide safe, healthy, and sustainable environments for people to live and work. Well-designed building regulations can advance development agendas, including disaster and chronic risk reduction, climate change mitigation and adaptation, disability and inclusive urban development, cultural heritage, and reconstruction processes. The program is aligned with a shift from disaster response and recovery to ex-ante disaster risk reduction for buildings and infrastructure.

The BRR Program aims to contribute to the reduction of human and economic losses by developing more efficient and effective building regulatory frameworks. BRR supports governments to strengthen technical standards in formal and informal settlements; lay secure foundation for public and foreign investment through protection of physical assets; and develop more efficient land management and mapping tools. BRR engagements provide technical assistance to help governments integrate and implement building regulatory components into World Bank Group supported operations.

Through its framework, BRR promotes effective building regulatory frameworks through three main areas of intervention: (i) supporting best practice national legislative frameworks, national institutions, and incentives that promote safe building practices; (ii) assisting in modern and locally-appropriate building code development and maintenance; and (iii) improving local systems of implementation of appropriate standards of land use and construction. BRR engagements are adapted to country-specific needs, ensuring that a wide range of relevant partners are included in the process, including the public sector, private sector, academia, and civil society. This approach ensures determining comparative strengths and experiences in local building sectors.

The Building Regulatory Capacity Assessment (BRCA) is a baseline assessment methodology developed by the BRR Program. It identifies concrete priority actions to advance the resilience of the built environment in each specific country context. 


\section{Acknowledgements}

The note is the result of collaborative effort between the Royal Government of Bhutan (RGoB) and the World Bank Group (World Bank). The South Asia Region Disaster Risk Management and Climate Change team prepared the note. The stakeholders include: the Department of Engineering Services, Department of Human Settlement, Department of Roads, and Division of Policy and Planning of the Ministry of Works and Human Settlement; Department of Disaster Management of the Ministry of Home and Cultural Affairs; National Center for Hydrology and Meteorology; Ministry of Finance and Thimphu Thromde.

The note presents the emerging challenges in the context of increasing urbanization and vulnerability to weather, water, and climate hazards. It is intended to guide the RGoB in the prioritization of its investments and the Bank in future analytical and investment support on urban- and resilience-related challenges.

The authors wish to extend their appreciation to the above agencies and in particular the Ministry of Works and Human Settlement in spearheading this task. We are especially grateful to Mr. Mahesh Pradhan, Project Manager of BUDP2; Mr. Tshering Dorji, Deputy Chief Planning Officer, MoWHS; Mr. Karma Dupchuk, Director of Engineering Services, MoWHS; Mr. Sonam Yangdhen, Executive Engineer, Engineering Adaptation and Risk Reduction Division, DES; Mr. Dechen Norbu, Chief Engineer, Engineering Services Division, DES; Mr. Namgyel Wangchuk, ESD, DES; Ms. Tshering Pelden, Engineer, ESD, DES; Ms. Kunzang Choden, Deputy Executive Engineer, Flood Engineering and Management Division, DES; Mr. Karma Sonam, Director of Human Settlement, MoWHS; Mr. Tashi Penjor, Chief Urban Planner, DHS; Ms. Bhawana Chhetri, Deputy Chief Planner, DHS; Ms. Thinley Choden, Principal Engineer, Water and Sanitation Division, DES; Mr. Dhan Raj Chhetri, Engineer, Department of Roads, MoWHS; Mr. Tshering Wangchuk, Program Officer, Department of Disaster Management, Ministry of Home and Cultural Affairs; Mr. Tayba Buddha Tamang, Executive Engineer, National Center for Hydrology and Meteorology; Mr. Bikash Pradhan, Deputy Executive Engineer, NCHM; Mr. Sonam Penjor, Chief Planning Officer, Ministry of Finance; Mr. Tshering Tashi, Deputy Chief Planning Officer, MoF; and Mr. Karma Jamtsho, Chief Engineer, Thimphu Thromde.

We would especially like to acknowledge the guidance and support from the Honorable Minister Mr. Lyonpo Dorji Tshering, Honorable Secretary Mr. Chencho Dorji, and the preceding Honorable Secretary Mr. Chencho Norbu.

The World Bank team that prepared this note includes Dechen Tshering, Disaster Risk Management Specialist, and Arati Belle, Disaster Risk Management Specialist. The team is grateful to the following for their inputs and comments: Tenzin Lhaden, Operations Officer; Keiko Sakoda, Disaster Risk Management Specialist; Zahed H. Khan, Senior Urban Specialist; Balakrishna Menon Parameswaran, Lead Urban Specialist; David Ryan Mason, Urban Development Specialist; and Marc S. Forni, Lead Disaster Risk Management Specialist.

Special thanks are due to Christoph Pusch, Practice Manager, DRM and Climate Change, SAR; Catalina Marulanda, Practice Manager, Urban, SAR; Yoichiro Ishihara, Resident Representative of Bhutan Country Office; and Sanjay Srivastava, Program Leader for their guidance and continued support. 